\title{
Limb activation ameliorates body-related deficits in spatial neglect
}

\author{
S. Reinhart ${ }^{1 *}$, L. Schmidtt ${ }^{1,4}$, C. Kuhn ${ }^{1}$, A. Rosenthal ${ }^{1}$, T. Schenk ${ }^{3}$, I. Keller ${ }^{2}$ and G. Kerkhoff ${ }^{1,4}$ \\ Clinical Neuropsychology Unit and Outpatient Service, Saarland University, Saarbruecken, Germany \\ 2 Schön Clinic Bad Aibling, Clinical Neuropsychology, Bad Aibling, Germany \\ ${ }^{3}$ Department of Neurology, Erlangen University, Erlangen, Germany \\ ${ }^{4}$ International Research Training Group 1457 "Adaptive Minds," Saarbruecken, Germany
}

\section{Edited by:}

Mario Bonato, University of Padova,

Italy

\section{Reviewed by:}

Alessandro Farne, Institut National de la Santé et de la Recherche

Médicale, France

Anna Berti, University of Turin, Italy

*Correspondence:

S. Reinhart, Clinical

Neuropsychology Unit, Building

A 1.3., D-66123 Saarbruecken,

Germany.

e-mail: s.reinhart@mx.uni-saarland.de
Many neglect patients show deficits in the mental representation of their contralesional body side or body parts, termed personal neglect. These deficits include impairments in identifying body parts on schematic drawings of human bodies. Limb activation and alertness cues have been shown to modulate neglect transiently, and are effective treatments for several symptoms of the neglect syndrome. Here, we tested on eight patients with right-hemispheric stroke and left-sided spatial neglect whether these two techniques modulate deficits in the mental representation of hands, assessed with a hand-test in which the subjects had to decide whether a depicted schematic hand belongs to the left or right side of the human body. The results showed that neglect patients made marginally significant $(p=0.065)$ more errors in left-hand-decisions than right-hand-decisions, indicating a neglect-specific disorder. Moreover, we found that left-sided limb activation but not non-lateralized alertness cueing (a loud noise immediately before patients made their perceptual decision) significantly reduced misidentifications for depicted left hands as compared to baseline. No effect of any intervention was observed on error rates for depicted right hands. We conclude that the amelioration of the performance in the hand task is modulated by the activation of the body schema or other body representations through left-sided limb activation.

Keywords: personal neglect, body schema, representational neglect, body representational neglect, limb activation, phasic alerting, treatment, rehabilitation

\section{INTRODUCTION}

Neglect as a failure to report, respond, or orient to contralesional stimuli (Heilman et al., 2000) may affect extrapersonal or personal space. Many of these patients fail to use or recognize the contralesional side of their body, an impairment which is termed personal neglect (Adair et al., 1995) or body representational neglect (Glocker et al., 2006). Personal neglect is frequently observed after lesions of the right hemisphere, but also after left hemispheric lesions (Groh-Bordin et al., 2009). The incidence is estimated to be up to about $45 \%$ in right hemispheric damaged patients, depending on the study and the used assessment instrument (Bisiach et al., 1986; Zoccolotti and Judica, 1991; Bowen et al., 2005; Groh-Bordin et al., 2009; Baas et al., 2011).

Personal neglect has been considered to be the origin of, or to be closely associated with, several neglect related impairments, including unilateral premotor deficits (Heilman et al., 1985), the misrepresentation of extrapersonal space (Bisiach, 1993; Umilta, 1995), and the disruption of the body-centered reference system (Karnath, 1994). However, although extrapersonal and personal impairments are often observed together as a symptom cluster in neglect patients, some studies using tests developed to assess personal neglect specifically like the Fluff-Test (Cocchini et al., 2001) the Vest Test (Glocker et al., 2006), or the Comb-and-Razor-Test (Beschin and Robertson, 1997; McIntosh et al., 2000) have found evidence of a double dissociation of these symptoms, both on the behavioral and anatomical level (Bisiach et al., 1986; Zoccolotti and Judica, 1991; Bowen et al., 2005; Committeri et al., 2007; Baas et al., 2011). Therefore, personal neglect seems to be only one aspect of the multifactorial heterogenous neglect syndrome that has been shown to occur in several sensory modalities and may also include motor neglect.

Disorders associated with body representational neglect include impairments of identifying body parts on schematic drawings of human bodies. As a possible origin of these impairments, some authors (Coslett, 1998; Baas et al., 2011) suggested an impaired mental body schema, respectively, a reduced access to this schema, which can be understood as a three-dimensional, dynamic representation of the spatial and biomechanical features of the own body (Coslett, 1998; Gallagher, 1998). Some authors postulate this mechanism to be responsible for the cortical representation of the trunk surface (Berlucchi and Aglioti, 1997) and peripersonal space (Graziano and Gross, 1998), whereas Cardinali et al. (2009) pointed out that peripersonal space and the body schema might be tightly related but distinct concepts with different sensory inputs (vision, audition, and touch vs. proprioception, kinesthetic, and touch), functional properties (defensive movements and voluntary actions vs. unconscious body knowledge for action), and neural mechanisms (parieto-frontal 
bimodal neurons vs. prefrontal and parietal cortex). Furthermore, other authors distinguish these space and action-related concepts from a semantic and lexical representation of the body (body part names, functions, and relations with objects), termed body image (Coslett et al., 2002; Schwoebel and Coslett, 2005). Even if the psychological validity of the concept "body schema" and the number of different body representations can be debated (Bisiach, 1993; Cardinali et al., 2009), there are several studies that support this concept (as defined above) with evidence (McCloskey, 1978; Lackner, 1988; Iriki et al., 1996; Maravita et al., 2003; Mussap and Salton, 2006). Moreover, the debates about the psychological validity of this concept may have in part been provoked by the inconsistent use of the term "body schema" in different studies (Poeck and Orgass, 1971; Gallagher, 1998; for a recent view on this topic see Berlucchi and Aglioti, 2010). For example, both body representational neglect and apraxia (Schwoebel et al., 2004) after left-hemispheric lesions are based on the concept of a body schema. Both disorders are associated with impaired knowledge about body parts, their position in space, and their spatial relationship. However, Groh-Bordin et al. (2009) found that the two disorders form a double dissociation at the behavioral and anatomical level.

Several studies indicated that healthy subjects use their own body schema to decide whether a depicted body part belongs to the left or the right side of the body (Cooper and Shepard, 1975; Sekiyama, 1982; Parsons, 1987a,b, 1994). For example, Parsons (1994) showed that the actual observer's own position affects the speed with which the observer can decide whether a depicted rotated hand (the palm or the back of a hand) is a left or a right hand. In his study, the subjects' reaction times for the left or right hand judgments were similar to the time the participants needed for a real movement of their own hand into the requested position. Therefore, it can be concluded that humans make those left-right judgments of displayed hands by mentally rotating the representation of their own hands (Cooper and Shepard, 1975; Sekiyama, 1982; Parsons, 1987b). Interestingly, Coslett (1998) found that patients with personal neglect are impaired in identifying depicted left-sided body parts. The patients were asked to name photographs of left or right hands. They labeled the right hand drawings more reliably than those of the left hand. In contrast, control patients without neglect did not name the left hands with a reduced reliability. Coslett (1998) concluded, that the impairment of patients with body neglect in identifying left hands is related to a disturbed schema of the left half of the body. In a recent study Baas et al. (2011) replicated this finding. Furthermore, judging errors for left hands were the best predictor of personal neglect compared to other variables like extrapersonal neglect, somatosensory or motor impairments, or deficits in the representation of the left-sided extrapersonal space. The results of Coslett (1998) and Baas et al. (2011) can be explained by the findings of Parsons et al. (Parsons and Fox, 1998; Parsons et al., 1998) according to which sensorimotor representations of the body or body parts are controlled by areas in the hemisphere contralateral to the limb. Therefore, it is plausible that lesions of these brain areas affect the mental simulation of movements that are associated with the correct identification of left or right hands. In summary, it can be hypothesized that the disruption of, or a reduced access to the actual representation of the own body features, the body schema, is responsible for the impairment of patients with body neglect in identifying left hands.

Based on different explanations of the neglect syndrome, several treatments have been developed and evaluated in the last decades (for review see Kerkhoff, 2003; Kerkhoff and Schenk, 2012). Most of them aim to modulate the rightward bias in spatial attention and exploration of neglect patients by providing additional sensory or motor input. One of these bottom-up treatments is limb activation. During limb activation, the patient is asked to make limb movements with their contralesional arm while performing spatial tasks. These movements reduce neglect symptoms, including motor impairments (Robertson et al., 2002), visual and sensory neglect (Robertson and North, 1993), and motor extinction (Robertson and North, 1994). Robertson and North (Robertson and North, 1992, 1993) favor the active movement of limbs to be the critical factor that alleviates neglect symptoms. Unfortunately, as many stroke patients suffer from paresis of the contralesional limbs or the whole contralesional side of the body, active limb activation is no appropriate treatment for a large group of patients. However, a few studies have shown that passive limb movements can improve neglect signs as well (Ladavas et al., 1997; Frassinetti et al., 2001; Harding and Riddoch, 2009). Several studies have shown that specifically the position of the left hand (which has to be placed in the left hemispace) rather than the active movement seems to be the critical factor to ameliorate neglect symptoms in the peri-personal space (Halligan et al., 1991; Robertson and North, 1993; Ladavas et al., 1997; Frassinetti et al., 2001). Therefore, the effects of passive as well as of active limb activation on neglect can be traced back to the additional (sensory) proprioceptive input which the limb movement provides.

Several attentional systems can be affected in neglect (Van Vleet et al., 2011). In addition to the pathological rightward bias in spatial attention, neglect patients often show an impaired nonspatial tonic alertness which is associated with large lesions of the right hemisphere including frontal areas (Wilkins et al., 1987; Pardo et al., 1991; Whitehead, 1991; Shallice et al., 2008). Several studies provided evidence supporting the idea that both attentional systems are closely linked and that impairments in tonic alertness may enhance the spatial bias of neglect patients to the right (Posner, 1993; Robertson et al., 1995, 1997, 1998; Sturm et al., 2006). Consequently, it is plausible that central alerting cues may alleviate spatial neglect. Robertson et al. (1998) examined this theory by having their patients make temporal order judgments whereby a left-sided, visually presented bar was preceded or followed by a similar bar presented on the right side. Neglect patients tend to perceive the right-sided stimuli first even when this stimulus was in fact preceded by the stimulus on their left side. Robertson and colleagues (1998) found that presenting a loud (centrally presented) noise just before patients take their decision will reduce this spatial bias.

In summary, there is ample evidence showing that limb activation and phasic alerting modulate a variety of visual or sensory deficits in patients with left-sided neglect. But what about deficits that are associated with body neglect? Studies evaluating effects of limb activation or alertness cueing on body neglect related 
symptoms, such as a disturbed body schema, are not available to the best of our knowledge, although body neglect is not an infrequent phenomenon after brain damage (Glocker et al., 2006). In the present study, we examined whether these two treatments have the potential to modulate the disturbed body schema of patients with personal neglect.

\section{MATERIALS AND METHODS PATIENTS}

Eight patients (Mean age $=61.1$ years; SD $=12.1$ ) with righthemispheric stroke and moderate to severe left-sided visual neglect (assessed with four conventional neglect screening tests, namely paragraph reading test, horizontal line-bisection, number cancellation and drawing figures; for details see Utz et al., 2011) were included. All patients also showed moderate to severe left-sided body neglect (see Table 1), assessed with the standardized vest test (see Glocker et al., 2006; Groh-Bordin et al., 2009). This test requires the blindfolded patient to search for 24 objects (12 on either trunk side) placed in pockets on the front side of a vest she/he wears, using his/her ipsilesional hand. The subject is required to search as quickly as possible for all objects and handle them to the experimenter. Normative values are available from 25 healthy subjects performing the test with their right hand, and 25 healthy subjects performing the test with their left hand (Glocker et al., 2006).

The mean interval from stroke to testing was 9.8 weeks $(\mathrm{SD}=5.7)$. All subjects had a decimal visual acuity of at least 0.70 (20/30 Snellen equivalent) for the near viewing distance of $0.4 \mathrm{~m}$ (see Table 1 for clinical and demographic details). Brain lesions were confirmed by magnetic resonance imaging (MRI) or computed tomography (CT) scans, and lesioned areas were mapped onto a standard MRI template using MRIcro software (Rorden and Brett, 2000). Figure 2 shows lesion maps of six of the patients. From two patients (Pt. 4 and 8) radiological images were no longer available for lesion mapping. All participants were informed of the experimental protocol which was conducted in accordance with the Declaration of Helsinki II and gave their written informed consent prior to their participation in the study. The study was approved by the ethics committee of the LudwigsMaximilian-Universität, München/Germany, Project Nr. 352-09 in November 2009.

\section{HAND TEST}

The hand-test used in the present study was developed based on the studies of Cooper and Shepard (1975); Parsons (1994); Coslett (1998). The stimuli included 24 schematic line drawings of the palm or the back of left or right human hands (see Figure 1). The stimuli (only one at a time) were presented centrally on a $15^{\prime}$ computer screen in randomized order. The patients were asked to decide whether the drawing depicted a left or a right human hand and they were instructed to imagine their own hand to facilitate the identification of the drawings. The response time was not limited. To rule out visual comparisons of the own and the depicted hands, the hands of the patients were covered with a black blanket. The patients' verbal responses were recorded by one examiner. No feedback of their performance was given to the patient in any of the experimental conditions.

\section{LIMB ACTIVATION AND ALERTNESS CUEING}

The patients sat in front of the computer screen with their eyes aligned with the center of the screen. For the passive-limbactivation intervention we adopted the protocol from the study of Frassinetti et al. (2001). During the assessment period the lower left arm of the patient was continuously stretched and flexed passively by an examiner up to a $45^{\circ}$ angle and with a frequency of about 1.5 movements per second. The palm of the hand was

Table 1 | Clinical and demographic data of the eight patients with left visual neglect after a single vascular lesion of the right hemisphere.

\begin{tabular}{|c|c|c|c|c|c|c|c|c|c|}
\hline Patient & Age, sex & Etiology & Localization & $\begin{array}{l}\text { Weeks post } \\
\text { lesion }\end{array}$ & $\begin{array}{l}\text { Body neglect } \\
\text { (omissions L-R } \\
\text { side) }\end{array}$ & $\begin{array}{l}\text { Reading } \\
\text { omissions }\end{array}$ & Figure copy & Line bisection & $\begin{array}{l}\text { Number } \\
\text { cancellation }\end{array}$ \\
\hline 2 & $60, W$ & $\mathrm{MCl}$ & Th & 7 & $8 / 1$ & + & + & - & - \\
\hline 3 & $81, W$ & $\mathrm{MCl}$ & $\mathrm{FL}, \mathrm{TL}, \mathrm{PL}$ & 11 & $12 / 7$ & - & - & + & - \\
\hline 4 & $68, W$ & $\mathrm{MCl}$ & $*$ & 4 & $10 / 4$ & - & - & - & - \\
\hline 6 & $65, W$ & $\mathrm{MCl}$ & $*$ & 23 & $7 / 5$ & - & - & - & - \\
\hline 7 & $64, M$ & $\mathrm{MCl}$ & $\mathrm{BG}, \mathrm{TL}, \mathrm{PL}$ & 5 & $4 / 4$ & - & - & - & - \\
\hline 8 & $39, \mathrm{M}$ & $\mathrm{MCl}$ & $\mathrm{BG}$ & 8 & $9 / 8$ & - & - & - & - \\
\hline Mean & 61.1 years & & & 9.8 weeks & $\begin{array}{l}8 / 8-7 / 8^{*} \\
\text { impaired }\end{array}$ & $\begin{array}{l}7 / 8 \\
\text { impaired }\end{array}$ & $\begin{array}{l}\text { 6/8 } \\
\text { impaired }\end{array}$ & $\begin{array}{l}7 / 8 \\
\text { impaired }\end{array}$ & $\begin{array}{l}\text { 8/8 } \\
\text { impaired }\end{array}$ \\
\hline
\end{tabular}

Abbreviations: $\mathrm{MCl}$, middle cerebral artery infarction; ACl, anterior cerebral artery infarction; BG, basal ganglia; Th, Thalamus; FL, Frontal Lobe; TL, Temporal Lobe; PL, Parietal Lobe; *, No imaging available. Neglect screening tests: -, impaired; +, normal performance. Reading omissions: Paragraph reading of a 150 word reading test (normal cutoff max two omissions). Figure copy: Left sided omissions or distortions. Line bisection: normal cutoff max 5 mm deviation to the right. Number cancellation: normal cutoff: max two omissions on the left side (for details see Utz et al., 2011). Body neglect test: Vest test (see Glocker et al., 2006), cutoff scores: max three omissions for left/right side (from 12 targets on each trunk side); *Eight from eight patients were impaired for the left vest test side, seven from eight patients were impaired for the right vest side, but with a less marked impairment. 

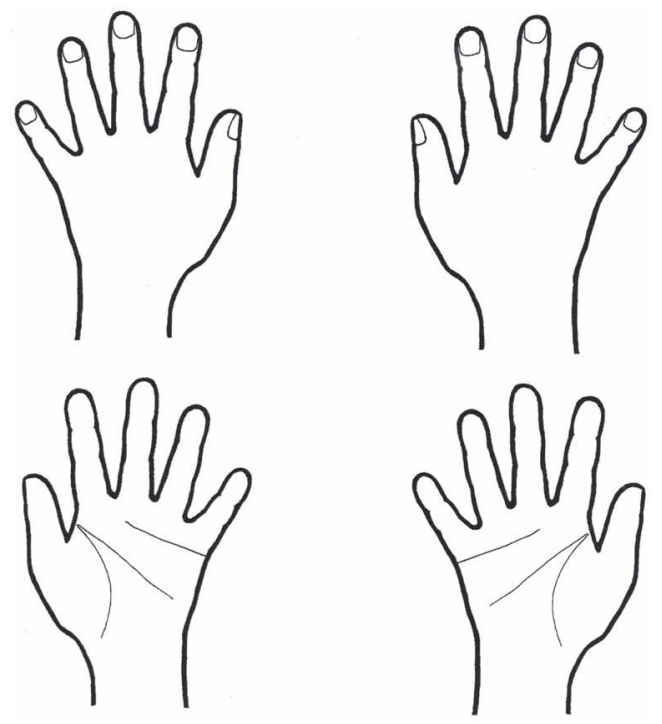

FIGURE 1 | Examples of hand stimuli. The schematic drawing could depict the palm or the back of a left or a right hand. Hands were shown as single stimulus (see Materials and Methods).

oriented toward the patient. The elbow of the arm rested on the table in front of the patient on the left side of space, the upper arm, and the trunk forming an angel of about $35-55^{\circ}$. As noted above, the moving left arm was covered with a black blanket and the right arm rested without any movement and invisible for the patient under the table on his right leg. The limb activation began 5 min before the hand-test task.

For the alertness-cueing intervention we adopted the protocol from the study by Robertson et al. (1998). The alertness cue $(2200 \mathrm{~Hz}, 65-80 \mathrm{~dB}, 350 \mathrm{~ms}$ duration) was presented $1000 \mathrm{~ms}$ before the presentation of every visual stimulus via an external loudspeaker which was connected to the PC used for the visual stimulus presentation. To prevent spatial cueing the acoustic cue was presented from a central position relative to the observer's body midline in $0.80 \mathrm{~m}$ distance.

The patients were instructed to identify immediately after the presentation of the visual stimulus whether the picture represented a left or a right hand.

All experimental conditions were implemented in a randomized order to rule out sequence or test adaptation effects. The visual neglect tests were assessed at the beginning of the first and at the end of the second session. The whole experiment was realized within one week in two sessions of about one hour each.

\section{RESULTS}

A $T$-test for repeated measurements (one-tailed) revealed a marginally significant difference between left- and righthand-judgments in the baseline measurement $\left[T_{(7)}=1.710\right.$; $p=0.065]$. An ANOVA for repeated measurements with the factors Treatment (Baseline, Limb Activation, Alertness Cueing) and Hand-Side (schematic pictures of left or right hands) revealed a significant effect of Treatment $\left[F_{(2,14)}=3.951 ; p=0.044\right.$, $\left.\eta_{p}^{2}=0.361\right]$ and a marginally significant effect of Hand-Side $\left[F_{(1,7)}=5.029 ; \quad p=0.060 ; \eta_{p}^{2}=0.418\right]$. The Treatment $\times$ Hand-Side interaction $\left[F_{(2,14)}=1.047 ; p=0.377 ; \eta_{p}^{2}=0.130\right]$ was not significant. Subsequent $T$-Tests for repeated measurements were computed for a more specific examination of the treatment effects for each hand-side separately. For left hands the analysis (one tailed) revealed a significant reduction in decision errors for Limb Activation $\left[T_{(7)}=2.200 ; p=0.032 ; d=0.77\right]$, but not for Alertness Cueing $\left[T_{(7)}=0.659 ; p=0.265 ; d=0.23\right.$ ] compared to the Baseline. There was also a significant difference between the two treatments Limb Activation and Alertness Cueing $\left[T_{(7)}=-2.570 ; p=0.037 ; d=0.91\right.$; two-tailed $]$. For the right side, $T$-Tests revealed no significant differences between any of the conditions. Results are depicted in Figure 3.

$T$-Tests for repeated measurements revealed no significant differences between the first and the second assessment of the visual neglect paragraph reading test [left-sided word omissions; $T_{(7)}=1.24 ; p=0.25$ ], horizontal line-bisection deviation $\left[T_{(7)}=-0.16 ; p=0.89\right]$ and number cancellation [left-sided omissions; $\left.T_{(7)}=-0.89 ; p=0.40\right]$.

\section{DISCUSSION}

In this study, we examined to which extent limb activation and alertness cueing can modulate signs of personal neglect assessed with a schematic hand discrimination task (left vs. right hand judgment). Unfortunately, there was only a marginal significant higher error rate for the identification of left hands as contrasted to depicted right hands. However, as the $p$-value (0.065) is close to the significance level of $p=0.05$ our finding can cautiously be interpreted in line with the findings of Coslett (1998) and Baas et al. (2011) that neglect patients show a deficit in the identification of left hands related to their disorder. Several studies support the theory that subjects use their own body schema to identify depicted body parts, specifically hands. Therefore, the deficit of the participating patients in identifying left hands can be interpreted in favor of an impaired left-sided body schema (Coslett, 1998) for the left body side or in terms of a reduced access to this body representation of their left side. Another possible explanation is that patients with personal neglect principally could use their (unimpaired) body schema for hand identifications and simply do not use it because of their attentional neglect for the left side. Alternatively, it may be also hypothesized that this effect could be due to activation of other body representations beyond the body schema, i.e., body image, or motor imagery. This might explain why the body schema-which is typically conceived as an "unconscious" body representation-was modulated although our patients were explicitly (hence consciously) instructed to imagine their hands during the experiment.

Even if the effect of Hand-Side was only marginally significant and there was no significant interaction of Hand-Side $\times$ Treatment observable, we think that three significant effects are noteworthy because they possibly indicate an advantage of limb activation over alertness cueing in manipulating the disturbed identification of left hands in neglect. First, there was a significant main effect of Treatment indicating that the identification of depicted hands can be manipulated. Second, subsequent 

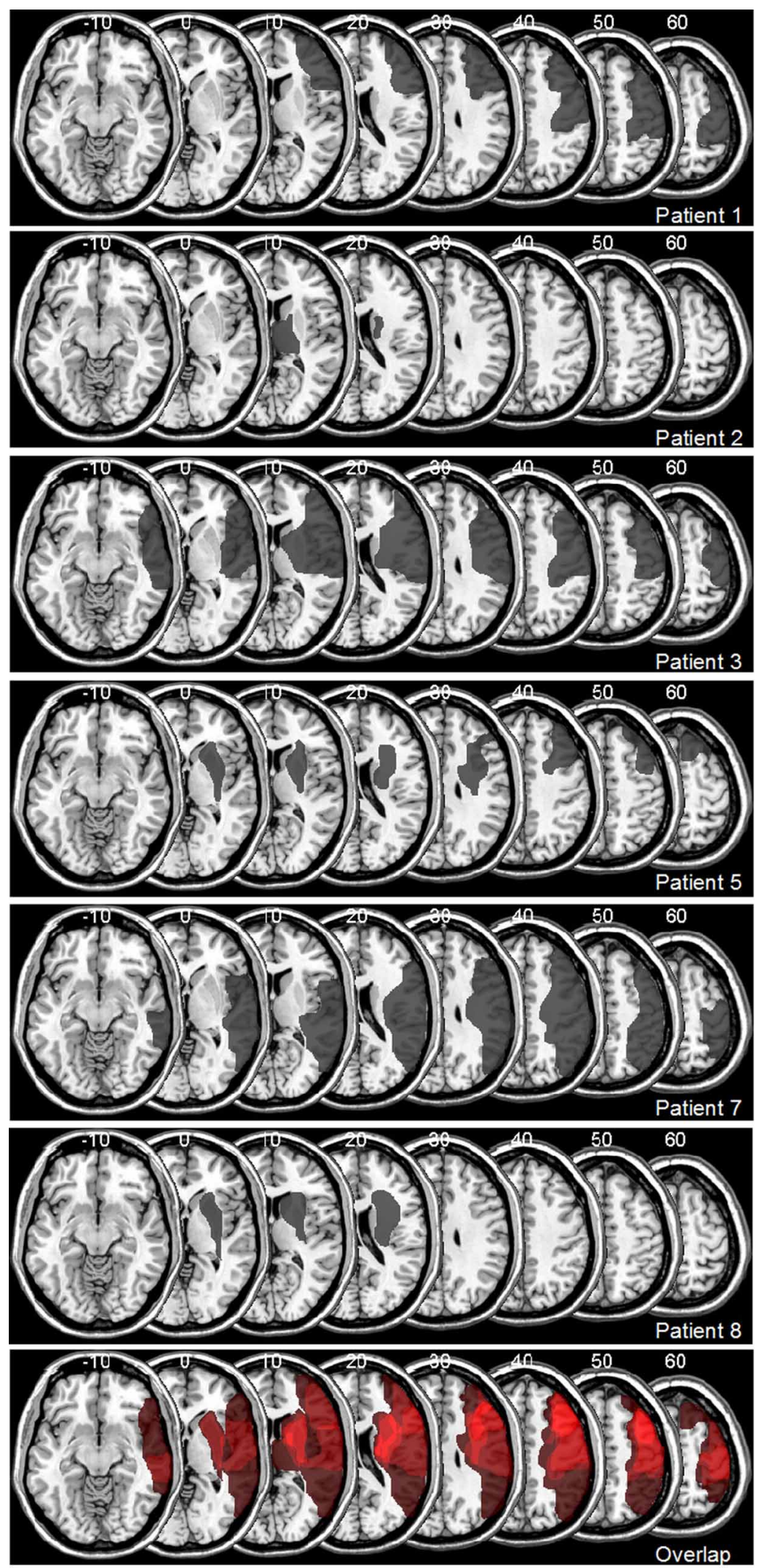

FIGURE 2 | Lesion Maps for 6 out of 8 Patients with Visuospatial Neglect, Plotted onto a Normal Template Brain Using MRIcro Software (Rorden and Brett, 2000). Affected areas (translucent gray) are plotted onto axial slices, with numbers indicating Z-coordinates in Talairach space. 


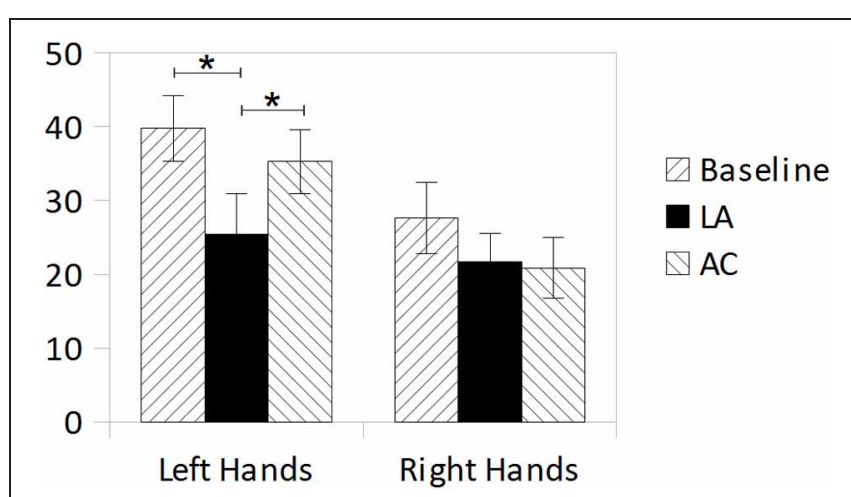

FIGURE 3 | Mean error rates (\%) in the hands-test during Baseline, Limb Activation, and Alertness conditions for depicted left hands (left bars) and depicted right hands (right bars). Error bars indicate standard errors of the mean (SEM).

analyses examining that effect revealed a significant reduction of misidentifications of left hands only during limb activation and no reduction during alertness cueing (both compared to the baseline). Third, there was a significant difference between limb activation and alertness cueing reflecting a greater reduction of misidentifications during limb activation. Therefore, it cautiously can be concluded that limb activation possibly has an advantage over alertness cueing in manipulating the disturbed identification of left hands in neglect patients. On the one hand, this result suggests that the body schema for left-sided body parts can be activated, at least in part, and therefore appears to be basically intact and accessible rather than completely destroyed. On the other hand, the results indicate that this activation has to be specifically body-related. An unspecific elevation of non-spatial alertness appears to be insufficient to alleviate the impairments in body representation observed in our small sample. However, as our results are not unambiguous and the lack of significance of the Treatment $\times$ Hand-Side interaction possibly is due to the small

\section{REFERENCES}

Adair, J. C., Na, D. L., Schwartz, R. L., Fennell, E. M., Gilmore, R. L., and Heilman, K. M. (1995). Anosognosia for hemiplegia: test of the personal neglect hypothesis. Neurology 45, 2195-2199.

Baas, U., de Haan, B., Grässli, T., Karnath, H. O., Mueri, R., Perrig, W. J., Wurtz, P., and Gutbrod, K. (2011). Personal neglect - a disorder of body representation? Neuropsychologia 49, 898-905.

Berlucchi, G., and Aglioti, S. (1997). The body in the brain: neural bases of corporeal awareness. Trends Neurosci. 20, 560-564.

Berlucchi, G., and Aglioti, S. M. (2010). The body in the brain revisited. Exp. Brain Res. 200, 25-35.

Beschin, N., and Robertson, I. H. (1997). Personal versus extrapersonal neglect: a group study of their dissociation using a reliable clinical test. Cortex 33, 379-384.

Bisiach, E. (1993). Mental representation in unilateral neglect and related disorders: the twentieth bartlett memorial lecture. Q. J. Exp. Psychol. A 46, 435-461.

Bisiach, E., Perani, D., Vallar, G., and Berti, A. (1986). Unilateral neglect: personal and extra-personal. Neuropsychologia 24, 759-767.

Bowen, A., Gardener, E., Cross, S., Tyrrell, P., and Graham, J. (2005). Developing functional outcome measures for unilateral neglect: a pilot study. Neuropsychol. Rehabil. 15, 97-113.

Cardinali, L., Brozzoli, C., and Farne, A. (2009). Peripersonal space and body schema: two labels for the

statistical power of our small sample, these hypotheses require further evaluation in subsequent studies with larger sample size.

These results would not only be of theoretical interest, but potentially also of clinical relevance. Passive limb activation has been found to decrease different neglect symptoms, particularly visual neglect (Ladavas et al., 1997; Frassinetti et al., 2001; Harding and Riddoch, 2009). Here we have shown that this treatment transiently modulates also the body schema which is disturbed in representational personal neglect. Currently we do not know whether it is also possible to obtain longer-lasting effects. Therefore, we will have to leave it to future research to determine whether limb-activation can be used as a treatment for personal neglect.

\section{LIMITATIONS OF THE STUDY}

While the present results suggest—in our view-an interesting modulation of body-related deficits in patients with visual and body-neglect using limb-activation, there are several limitations. First, the sample size was limited. Second, no non-neglecting control group with right-hemisphere damage was included, thus, we do not know whether the observed manipulations are specific to neglect or would occur in other subjects (patients or healthy controls) as well. Moreover, the statistical analysis showed only a marginally significant effect of Hand-Side (close but beyond $p=0.05$ ) and a non-significant Treatment $\times$ Hand-Side interaction. Finally, the precise mechanisms by which the typically unconscious body schema can be activated by an explicit (and hence initially conscious) instruction to imagine the own hands requires clarification in subsequent studies. Nevertheless, we believe that these admittedly preliminary results - which to our knowledge are the first on the modulation of this type of body-related deficits in spatial neglect-might stimulate interesting subsequent research. Furthermore, it might be interesting to evaluate whether such limb-activation effects might also be present in non-neglecting subjects, i.e., healthy subjects, or other clinical populations with body-related deficits, but without stroke.

same concept? Brain Topogr. 21, 252-260.

Cocchini, G., Beschin, N., and Jehkonen, M. (2001). The fluff test: a simple task to assess body representation neglect. Neuropsychol. Rehabil. 11, 17-31.

Committeri, G., Pitzalis, S., Galati, G., Patria, F., Pelle, G., Sabatini, U., Castriota-Scanderbeg, A., Piccardi, L., Guariglia, C., and Pizzamiglio, L. (2007). Neural bases of personal and extrapersonal neglect in humans. Brain 130, 431-441.

Cooper, L. A., and Shepard, R. N. (1975). Mental transformations in the identification of left and right hands. J. Exp. Psychol. Hum. Percept. Perform. 104, 48-56.

Coslett, H. B. (1998). Evidence for a disturbance of the body schema in neglect. Brain Cogn. 37, 527-544.
Coslett, H. B., Saffran, E. M., and Schwoebel, J. (2002). Knowledge of the human body: a distinct semantic domain. Neurology 59, 357-363.

Frassinetti, F., Rossi, M., and Ladavas, E. (2001). Passive limb movements improve visual neglect. Neuropsychologia 39, 725-733.

Gallagher, S. (1998). "Body schema and intentionality," in The Body and the Self, eds J. L. Bermudez, A. Marcel, and N. Glan (Cambridge, MA: MIT Press), 225-244. [1.paperback ed., 2. print. ed.].

Glocker, D., Bittl, P., and Kerkhoff, G. (2006). Construction and psychometric properties of a novel test for body representational neglect (Vest Test). Restor. Neurol. Neurosci. 24, 303-317.

Graziano, M. S., and Gross, C. G. (1998). Spatial maps for the 
control of movement. Curr. Opin. Neurobiol. 8, 195-201.

Groh-Bordin, C., Glocker, D., Bittl, P., Keller, I., Preger, R., Hildebrandt, H., and Kerkhoff, G. (2009). Scanning your body is different from performing body movements: a double dissociation between body representational neglect and apraxia. Neuropsychologia 47, 1187-1192.

Halligan, P. W., Manning, L., and Marshall, J. C. (1991). Hemispheric activation vs spatio-motor cueing in visual neglect: a case study. Neuropsychologia 29, 165-176.

Harding, P., and Riddoch, M. J. (2009). Functional electrical stimulation (FES) of the upper limb alleviates unilateral neglect: a case series analysis. Neuropsychol. Rehabil. 19, 41-63.

Heilman, K. M., Bowers, D., Coslett, H. B., Whelan, H., and Watson, R. T. (1985). Directional hypokinesia: prolonged reaction times for leftward movements in patients with right hemisphere lesions and neglect. Neurology 35, 855-859.

Heilman, K. M., Valenstein, E., and Watson, R. T. (2000). Neglect and related disorders. Semin. Neurol. 20, 463-470.

Iriki, A., Tanaka, M., and Iwamura, Y. (1996). Coding of modified body schema during tool use by macaque postcentral neurones. Neuroreport 7, 2325-2330.

Karnath, H. O. (1994). Subjective body orientation in neglect and the interactive contribution of neck muscle proprioception and vestibular stimulation. Brain 117(Pt 5), 1001-1012.

Kerkhoff, G. (2003). Modulation and rehabilitation of spatial neglect by sensory stimulation. Prog. Brain Res. 142, 257-271.

Kerkhoff, G., and Schenk, T. (2012). Rehabilitation of neglect: an update. Neuropsychologia 50, 1072-1079.

Lackner, J. R. (1988). Some proprioceptive influences on the perceptual representation of body shape and orientation. Brain 111(Pt 2), 281-297.

Ladavas, E., Berti, A., Ruozzi, E., and Barboni, F. (1997). Neglect as a deficit determined by an imbalance between multiple spatial representations. Exp. Brain Res. 116, 493-500.
Maravita, A., Spence, C., and Driver, J. (2003). Multisensory integration and the body schema: close to hand and within reach. Curr. Biol. 13, R531-R539.

McCloskey, D. I. (1978). Kinesthetic sensibility. Physiol. Rev. 58, 763-820.

McIntosh, R. D., Brodie, E. E., Beschin, N., and Robertson, I. H. (2000). Improving the clinical diagnosis of personal neglect: a reformulated comb and razor test. Cortex 36, 289-292.

Mussap, A. J., and Salton, N. (2006). A 'rubber-hand' illusion reveals a relationship between perceptual body image and unhealthy body change. J. Health Psychol. 11, 627-639.

Pardo, J. V., Fox, P. T., and Raichle, M. E. (1991). Localization of a human system for sustained attention by positron emission tomography. Nature 349, 61-64.

Parsons, L. M. (1987a). Imagined spatial transformation of one's body. J. Exp. Psychol. Gen. 116, 172-191.

Parsons, L. M. (1987b). Imagined spatial transformations of one's hands and feet. Cogn. Psychol. 19, 178-241.

Parsons, L. M. (1994). Temporal and kinematic properties of motor behavior reflected in mentally simulated action. J. Exp. Psychol. Hum. Percept. Perform. 20, 709-730.

Parsons, L. M., and Fox, P. T. (1998). The neural basis of implicit movements used in recognizing hand shape. Cogn. Neuropsychol. 15, 583-615.

Parsons, L. M., Gabrieli, J. D., Phelps, E. A., and Gazzaniga, M. S. (1998). Cerebrally lateralized mental representations of hand shape and movement. J. Neurosci. 18, 6539-6548.

Poeck, K., and Orgass, B. (1971). The concept of the body schema: a critical review and some experimental results 145 . Cortex 7, 254-277.

Posner, M. I. (1993). "Interaction of arousal and selection in the posterior attention network," in Attention: Selection, Arousal, Awareness, and Control - A tribute to Donald Broadbent, eds A. D. Baddeley and L. Weiskrantz (New York, NY: Oxford), 390-405.

Robertson, I. H., Manly, T., Beschin, N., Daini, R., Haeske-Dewick, H., Hömberg, V., Jehkonen, M., Pizzamiglio, G., Shiel, A., and Weber, E. (1997). Auditory sustained attention is a marker of unilateral spatial neglect. Neuropsychologia 35, 1527-1532.

Robertson, I. H., Mattingley, J. B., Rorden, C., and Driver, J. (1998). Phasic alerting of neglect patients overcomes their spatial deficit in visual awareness. Nature 395, 169-172.

Robertson, I. H., McMillan, T. M., MacLeod, E., Edgeworth, J., and Brock, D. (2002). Rehabilitation by limb activation training reduces left-sided motor impairment in unilateral neglect patients: a singleblind randomised control trial. Neuropsychol. Rehabil. 12, 439-454.

Robertson, I. H., and North, N. (1992). Spatio-motor cueing in unilateral left neglect: the role of hemispace, hand and motor activation. Neuropsychologia 30, 553-563.

Robertson, I. H., and North, N. (1993). Active and passive activation of left limbs: influence on visual and sensory neglect. Neuropsychologia 31, 293-300.

Robertson, I. H., and North, N. T. (1994). One hand is better than two: motor extinction of left hand advantage in unilateral neglect. Neuropsychologia 32, 1-11.

Robertson, I. H., Tegner, R., Tham, K., Lo, A., and Nimmo-Smith, I. (1995). Sustained attention training for unilateral neglect: theoretical and rehabilitation implications. J. Clin. Exp. Neuropsychol. 17, 416-430.

Rorden, C., and Brett, M. (2000). Stereotaxic display of brain lesions. Behav. Neurol.12, 191-200.

Schwoebel, J., Buxbaum, J., and Coslett, H. B. (2004). Representations of the human body in the production and imitation of complex movements. Cogn. Neuropsychol. 21, 285-298.

Schwoebel, J., and Coslett, H. B. (2005). Evidence for multiple, distinct representations of the human body. J. Cogn. Neurosci. 17, 543-553.

Sekiyama, K. (1982). Kinesthetic aspects of mental representations in the identification of left and right hands. Percept. Psychophys. 32, 89-95.

Shallice, T., Stuss, D. T., Alexander, M. P., Picton, T. W., and Derkzen, D. (2008). The multiple dimensions of sustained attention. Cortex 44 , 794-805.
Sturm, W., Schmenk, B., Fimm, B., Specht, K., Weis, S., Thron, A., and Willmes, K. (2006). Spatial attention: more than intrinsic alerting? Exp. Brain Res. 171, 16-25.

Umilta, C. (1995). Domain-specific forms of neglect. J. Clin. Exp. Neuropsychol. 17, 209-219.

Utz, K. S., Keller, I., Kardinal, M., and Kerkhoff, G. (2011). Galvanic vestibular stimulation reduces the pathological rightward line bisection error in neglect-a sham stimulation-controlled study. Neuropsychologia 49, 1219-1225.

Van Vleet, T. M., Hoang-duc, A. K., DeGutis, J., and Robertson, L. C. (2011). Modulation of non-spatial attention and the global/local processing bias. Neuropsychologia 49, 352-359.

Whitehead, R. (1991). Right hemisphere processing superiority during sustained visual attention. J. Cogn. Neurosci. 3, 329-334.

Wilkins, A. J., Shallice, T., and McCarthy, R. (1987). Frontal lesions and sustained attention. Neuropsychologia 25, 359-365.

Zoccolotti, P., and Judica, A. (1991). Functional evaluation of hemineglect by means of a semistructured scale: personal extrapersonal differentiation. Neuropsychol. Rehabil. 1, 33-44.

Conflict of Interest Statement: The authors declare that the research was conducted in the absence of any commercial or financial relationships that could be construed as a potential conflict of interest.

Received: 14 December 2011; accepted: 07 June 2012; published online: 22 June 2012.

Citation: Reinhart S, Schmidt L, Kuhn $C$, Rosenthal A, Schenk T, Keller I and Kerkhoff G (2012) Limb activation ameliorates body-related deficits in spatial neglect. Front. Hum. Neurosci. 6:188. doi: 10.3389/fnhum.2012.00188

Copyright (c) 2012 Reinhart, Schmidt, Kuhn, Rosenthal, Schenk, Keller and Kerkhoff. This is an open-access article distributed under the terms of the Creative Commons Attribution Non Commercial License, which permits noncommercial use, distribution, and reproduction in other forums, provided the original authors and source are credited. 